\title{
A CONJUNTURA SOCIAL BRASILEIRA REVISITADA
}

\author{
Argelina Cheibub Figueiredo \\ HAROLDO DA GAMA TORRES \\ RENATA MIRANDOLA BICHIR
}

\section{RESUMO}

Este artigo procura identificar o papel desempenhado pelo Estado durante os anos 1990 para assegurar a satisfação das "necessidades básicas" da população pobre no Brasil. Com base em dois surveys sobre o acesso dos $40 \%$ domicílios mais pobres da cidade de São Paulo a serviços públicos e políticas sociais, demonstra-se que a atuação do Estado continua determinante e que o quadro da situação da população mais pobre de São Paulo pouco se alterou em relação aos anos 1980.

PALAVRAS-CHAVE: pobreza; serviços públicos; políticas sociais; Estado.

\section{SUMMARY}

This article seeks to identify Brazilian State's efficiency in supplying "basical needs" for the poor population. Taking as a guideline two surveys concerning the access to public services and social policies of the 40\% poorest homes in the city of São Paulo, it suggests that State action remains crucial and that the general social condition of the poor has not improved significantly since the 1980's.

KEYWORDS: poverty; public services; social policies; State.

[1] Faria, V. "A Conjuntura Social Brasileira: Dilemas e Perspectivas". In: Novos Estudos Cebrap, n. 33, julho de 1992.
No artigo "A conjuntura social brasileira", publicado nesta revista em 1992, Vilmar Faria, reconhecendo por meio de uma análise comparativa o "atraso social" do país, chamava a atenção para o papel que o Estado havia desempenhado na chamada "década perdida", os anos 1980, para assegurar a satisfação das "necessidades básicas" da população pobre no Brasil. Contra o "indiscriminado ataque" à presença do Estado, Vilmar advertia:

Essa análise indica que é preciso caminhar devagar com o andor quando o santo é de barro: como as necessidades básicas elementares, especialmente para as camadas mais pobres da população, são atendidas pelos serviços públicos, é preciso terpresente que se a situação é ruim com os serviços sociais de caráter público em virtude de sua precariedade e ineficiência, muito pior seria a situação sem eles. Esses serviços oferecem à população pobre uma safety net (grifo do autor). Sua desorganização ou mesmo destruição, especialmente num contexto de crise, pode ter conseqüências graves. ${ }^{1}$ 
Naquele artigo, Faria argumentava que a década foi de fato perdida no que diz respeito às condições econômicas - experimentamos estagnação e alta inflação, diminuição do emprego e piora na distribuição de renda -, mas a área social testemunhou "avanços" que não foram desprezíveis. O autor lista alguns dos avanços ocorridos entre 1981 e 1989: aumento do número de anos de estudo e das taxas de alfabetização; diminuição do número de crianças com sintomas de desnutrição; diminuição dos domicílios considerados inadequados e da densidade dos domicílios; aumento de domicílios com água canalizada etc.

Neste artigo, pretendemos mostrar que o mesmo pode ser dito da década de 1990. Para isso, lançamos mão de dados de dois surveys sobreo acesso dos domicílios 40\% mais pobres da cidade de São Paulo a serviços públicos e a políticas sociais, realizados no Cebrap. O primeiro feito sob a coordenação de Vilmar Faria em 1991 e o segundo realizado em $2004 .^{2}$

Em primeiro lugar, apresentamos a evolução da situação de trabalho e geração de renda da população mais pobre do município nesse período. A segunda seção mostra os níveis de acesso da população mais pobre a serviços básicos nos dois momentos, destacando sua ampliação entre 1991 e 2004. A terceira seção trata dos mecanismos de acesso da população pobre à educação e à saúde e do modo como os avalia.

\section{TRABALHO E RENDA}

A evolução da situação de emprego dos $40 \%$ mais pobres de São Paulo entre 1991 e 2004 apresentou um quadro desalentador. Além da forte redução da proporção de ocupados em relação à população em idade ativa (PIA), que passou de 57,3\% em 1991 para $45,9 \%$ em 2004 , as condições associadas ao trabalho se deterioram substancialmente, como mostra a Tabela $1 .^{3}$

Em primeiro lugar, reduziu-se substancialmente a proporção de trabalhadores com carteira assinada, passando de 54\% em 1991 para 30\% em 2004. A contrapartida da queda no emprego formal se reflete nas taxas de crescimento do emprego sem carteira e de trabalho autônomo: ambas dobraram no período. De fato, a proporção de autônomos passou de $25 \%$ para $51 \%$ no mesmo período. Cabe destacar que, contrariando as tendências verificadas entre 1940 e 1980 em São Paulo, a década de 1990 caracteriza-se por uma queda muito expressiva do emprego formal, apontando para um quadro de significativa "desconexão" dos mais pobres com o mundo do trabalho, com impactos substanciais para as possibilidades de ascensão social e de integração à sociedade urbana contemporânea. ${ }^{4}$

Evidentemente, tal queda implicou uma redução expressiva no acesso a benefícios associados ao trabalho. Em primeiro lugar, a acentuada queda na contribuição social, de 66\% para $36 \%$. Tal indicador evidencia uma significativa exclusão dessa camada populacional dos benefícios previdenciários relevantes tais como auxílio-doença, salário
[2] Figueiredo, A., Torres, H, Limongi, F., Arretche, M., e Bichir, R. (2005). Relatório final do "Projeto BRA/04/052 - Rede de Pesquisa e Desenvolvimento de Políticas Públicas: REDE-IPEA II". Mimeo.
[3] Nos estudos de trabalho são utilizados, normalmente, dois indicadores diferentes nas avaliações de conjuntura: a taxa de ocupação, relação entre o total de ocupados e a população economicamente ativa (PEA), e a taxa de atividade, que relaciona a PEAà população em idade ativa (PIA). Por problemas de comparabilidade entre os dois surveys, consideramos aqui apenas a relação entre os ocupados e a PIA.
[4] Kaztman, R. e Retamoso, A. (2005). "Spatial segregation, employment and poverty in Montevideo". In: CEPAL Review n. 85, abril de 2005, pp. 125-141. 
TABELA I

Proporção de pessoas ocupadas com carteira assinada e que recebem benefícios associados ao trabalho.

São Paulo, 1991 e 2004.

\begin{tabular}{|c|c|c|}
\hline CATEGORIA & I99| & 2004 \\
\hline \multicolumn{3}{|c|}{ Situação de emprego (\%) } \\
\hline $\begin{array}{l}\text { Empregado } \\
\text { com carteira }\end{array}$ & 53,8 & 30,4 \\
\hline $\begin{array}{l}\text { Empregado } \\
\text { sem carteira }\end{array}$ & 7,51 & 14,8 \\
\hline Autônomos & 24,7 & 50,5 \\
\hline $\begin{array}{l}\text { Outras } \\
\text { situaçốes* }\end{array}$ & 14,0 & 4,3 \\
\hline Total & 100,0 & 100,0 \\
\hline \multicolumn{3}{|c|}{ Cobertura de beneficios trabalhistas (\%) } \\
\hline $\begin{array}{l}\text { Contribuição } \\
\text { INPS }\end{array}$ & 65,6 & 35,8 \\
\hline $\begin{array}{l}\text { Vale } \\
\text { transporte }\end{array}$ & 45,3 & 31,8 \\
\hline $\begin{array}{l}\text { Cesta básica } \\
\text { (no trabalho)/ } \\
\text { vale refeição }\end{array}$ & 77,9 & 35,9 \\
\hline
\end{tabular}

Fonte: Cebrap, 1991 e 2004.

-Trabalhadores em atividades familiares (com e sem remuneração) e empregadores.

família e aposentadoria por invalidez. A proporção de pessoas ocupadas que recebiam vale transporte, por suavez, caiu de $45 \%$ para $32 \%$. Aqueda na proporção dos empregados que recebem cesta básica no trabalho ou vale refeição foi ainda mais drástica: caiu de $78 \%$ para $36 \%$. Trata-se, sem dúvida, de um quadro dramático de perda de benefícios e de proteção social vinculados à legislação trabalhista.

Os efeitos desse quadro de significativa deterioração do trabalho podem ser observados ainda na composição interna da renda familiar mensal, que difere significativamente nos dois momentos no tempo. No caso dos homens, por exemplo, se destaca a queda da participação do trabalho principal na composição da renda e o aumento significativo da importância de trabalhos ocasionais (como bicos e trabalhos realizados em casa $e$ a participação das transferências governamentais, tais como aposentadorias), refletindo provavelmente uma queda no acesso à previdência social (Gráfico 1, abaixo).

No caso das mulheres, também se observa uma queda na relevância do trabalho principal e destaca-se principalmente o aumento da relevância dos rendimentos advindos de transferência de renda. Nesse grupo, o peso das transferências não se refere às aposentadorias, que eram menos freqüentes no passado, mas principalmente ao aumento das receitas relacionadas a programas de transferência de renda - como o Bolsa Família - muitos deles focados nos chefes de domicílio do sexo feminino.

Em resumo, o aumento da receita com trabalhos ocasionais (no caso dos homens) e com transferência de renda (no caso das mulheres) parece 
GRÁFICO I

Composição da renda familiar dos 40\% mais pobres, 1991 e 2004.

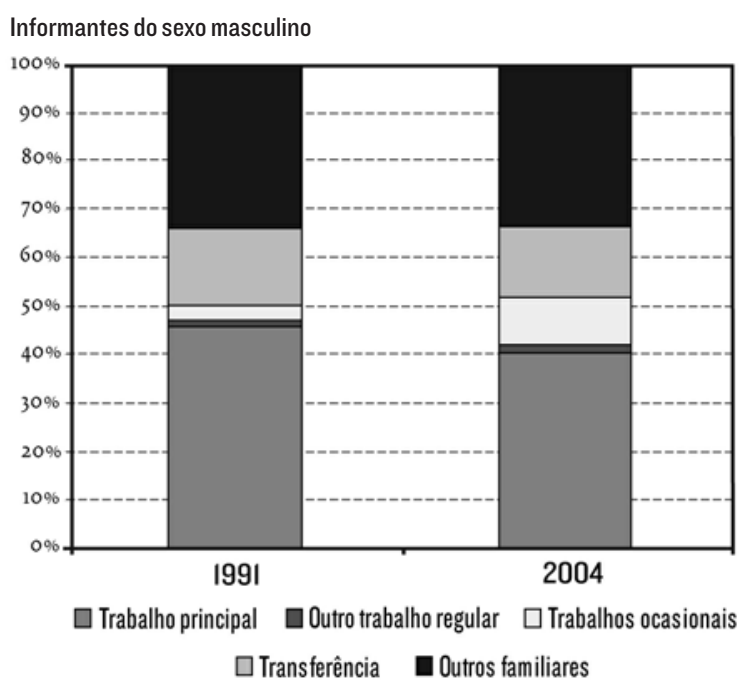

Informantes do sexo feminino

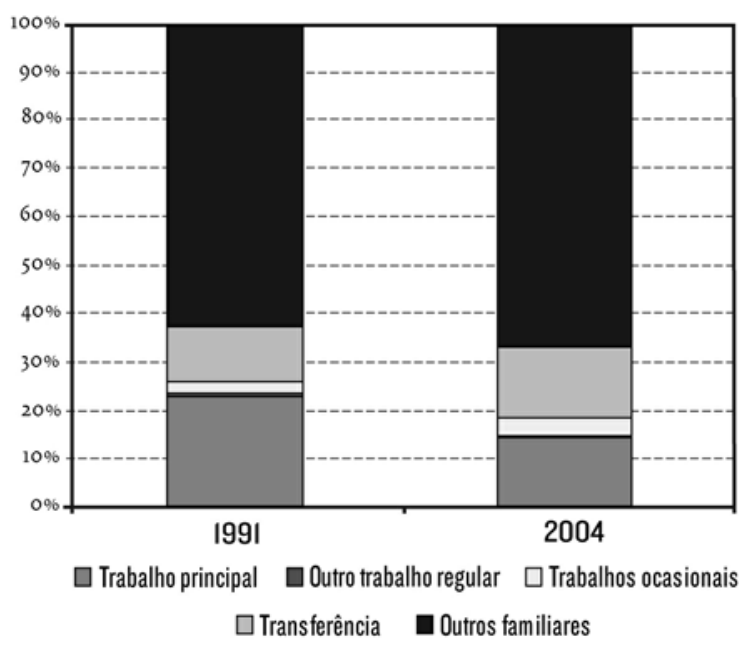

Fonte: Cebrap, 1991 e 2004.

ter contribuído para compensar as quedas na renda familiar oriundas de uma menor inserção dos mais pobres no mercado formal de trabalho. A inserção no mercado de trabalho atualmenteé muito mais precária do que a existente anteriormente, com extensas conseqüências para as possibilidades de ascensão e integração sociais, mas não necessariamente com um impacto muito substancial sobre a renda total auferida pelas famílias.

De fato, verificamos que o aumento da precariedade do trabalho parece não ter se refletido na renda familiar. Em 1991, o corte de renda dos 40\% mais pobres correspondia a 2,7 salários mínimos, enquanto, em 2004, esse corte se elevou para 4,2 salários mínimos (em valores de novembro de 2004). 5 Isso significa que a renda média dos $40 \%$ mais pobres aumentou substancialmente no período considerado. ${ }^{6}$ Cabe

[5] Os valores de 1991 foram inflacionados de acordo com o índice Fipe e foi realizada a devida conversão de moedas de Cruzeiro para Real.

[6] Infelizmente, não temos condições de comparar diretamente o rendimento médio efetivamente observado pelos trabalhadores pesquisados nos dois surveys, devido a problemas de ponderação da amostra de 1991. 
destacar, porém, que o ano de 1991 é relativamente problemático como período de referência, por se tratar de um dos piores anos em termos comparativos na série histórica de rendimentos médios.

\section{ACESSO A BENS DURÁVEIS}

Outro conjunto relevante de informações diz respeito à posse de bens duráveis. Esses dados mostram dois aspectos importantes da evolução das condições de vida da população mais pobre da cidade de São Paulo. Em primeiro lugar,em 1991, a posse de bens duráveis básicos - televisão, rádio, fogão e geladeira - jáera praticamente universal, tendo apenas este último, o mais caro deles, tido aumento significativo na década. Por outro lado, esses dados mostram a enorme expansão do acesso ao telefone fixo e a duplicação da proporção de domicílios que possui automóveis. Em segundo lugar, esses dados também mostram que o tamanho dos domicílios permaneceu praticamenteestável na década. Tanto o número médio de cômodos quanto o número de cômodos utilizados para dormir tiveram um aumento muito pouco significativo (Tabela 2).

TABELA 2

Posse de bens duráveis e características do domicílio dos $40 \%$ mais pobres. São Paulo, I991 e 2004.

\begin{tabular}{|c|c|c|}
\hline ITENS & I991 & 2005 \\
\hline \multicolumn{3}{|c|}{ Cobertura no acesso a bens } \\
\hline Televisão & $97,20 \%$ & $94,70 \%$ \\
\hline Fogão a gás & $98,50 \%$ & $98,10 \%$ \\
\hline Geladeira & $84,40 \%$ & $96,60 \%$ \\
\hline $\begin{array}{l}\text { Telefone } \\
\text { fixo }\end{array}$ & $6,20 \%$ & $57,10 \%$ \\
\hline Automóvel & $11,50 \%$ & $20,30 \%$ \\
\hline \multicolumn{3}{|c|}{ Caracteristicas do domicílio } \\
\hline $\begin{array}{l}\text { Número médio } \\
\text { de cômodos }\end{array}$ & 3,05 & 3,35 \\
\hline $\begin{array}{l}\text { Número } \\
\text { de cômodos } \\
\text { usados para } \\
\text { dormir }\end{array}$ & 1,53 & 1,63 \\
\hline
\end{tabular}

Fonte: Cebrap, 1991 e 2004

Embora não tenhamos dados comparativos para 1991, também encontramos em 2005 uma presença significativa do telefone celular (38,3\% do domićlíos), máquina de lavar (37,7\% dos domicílios com máquina com centrífuga), vídeo ou DVD (31,8\%) e computador ( $9,5 \%)$. Em outras palavras, fica claro que foram ampliadas as condições de acesso a bens duráveis. Vale porém advertir que, além de mudanças no nível de renda, esse aumento do consumo está provavel mente refletindo também outras mudanças na estrutura do consumo (com queda relativa 
dos preços de alimentos e duráveis) e à expansão do volume de crédito para os mais pobres, claramente derivado das políticas governamentais. ${ }^{7}$

Em síntese, os indicadores relacionados ao emprego e renda em São Paulo mostram uma forte deterioração das condições de acesso ao mercado de trabalho paralelamente a uma melhoria relativa da renda e de acesso a bens duráveis de consumo. Esse quadro éconsistente com o que ocorreu no nível nacional, embora o aumento da renda possa ser creditado a problemas decorrentes do fato de o ano de 1991 ser caracterizado como um dos piores das últimas décadas em termos de renda média, prejudicando assim essa comparação pontual. Depois de 1995, a renda média per capita familiar no Brasil ficou praticamente estabilizada, conforme os dados da PNAD.

\section{A OFERTA DE SERVIÇOS PÚBLICOS BÁSICOS}

O principal aspecto a ser destacado na comparação entre os serviços públicos oferecidos à população de baixa renda em São Paulo éo patamar relativamente alto já alcançado em 1991. Como sugeriu Faria, para essa cidade, a década de 1980 não parece ter sido de fato perdida. Esses serviços foram mantidos ou ampliados na década de 1990, mas considerando se tratar da mais rica metrópole do país, ainda não foram universalizados. Adois deles, cabe ressaltar, parcelas significativas da população ainda não têm acesso. A rede de esgotos, como mostra a Tabela 3, cresceu bastante, mas ainda não cobre um quarto da população, resultado que reflete a dificuldade encontrada pelos governos na década de 1990 de implementar políticas de investimento. No entanto,é a oferta de serviços de segurança a mais limitada em 1991 e que menor crescimento teve na década.

TABELA 3

Oferta de serviços públicos nos domicílios dos $40 \%$ mais pobres. São Paulo, 1991 e 2004.

\begin{tabular}{l|c|c}
\hline INDICADORES & $199 \mid$ & $\mathbf{2 0 0 4}$ \\
\cline { 1 - 1 } Rede de água & $94,0 \%$ & $96,7 \%$ \\
Energia elétrica & $98,1 \%$ & $97,4 \%$ \\
Coleta de lixo & $91,8 \%$ & $92,7 \%$ \\
Rede de esgoto & $61,2 \%$ & $75,0 \%$ \\
Ronda policial & $55,0 \%$ & $59,0 \%$ \\
\hline
\end{tabular}

Fonte: Cebrap, 1991 e 2004.

Tendo em vista o precário desenvolvimento das rondas policiais, não surpreende o significativo crescimento dos níveis de criminalidade. ${ }^{8}$ Além disso, como mostraremos mais adiante, o problema da segurança é percebido como o principal problema nas escolas públicas.

Finalmente, segundo os dados do survey de 2004 , a cobertura do ensino fundamental foi de $98,7 \%$ (não dispomos dessa informação para
[7] Torres, H.G., Bichir, R.M. e Carpim, T.P.(2006). “Uma pobreza diferente?". In: Novos Estudos Cebrap, n. 74, pp. 17-24.
[8] A taxa de óbitos por causas violentas no Estado de São Paulo mais do que duplicou ao longo da década de 1990 , segundo os dados da Fundação Seade, embora os índices tenham apresentado alguma queda a partir de 2003. 
1991). Considerando o tempo de permanência na escola, nota-se que em média as crianças ficam 4,4 horas na escola, porém esse dado apresenta variações significativas. Uma importante diferenciação refere-se ao tipo da escola:enquanto as crianças da rede municipal tendem a ficar em média 4,1 horas na escola, as crianças da rede estadual têm uma carga horária de 4,8 horas em média. Esse resultado é consistente com a política estadual de educação, que ampliou a carga horária no ensino fundamental, e evidencia o argumento de que para além da universalização, o Estado tem também se preocupado com a melhora na provisão dos serviços públicos.

Analogamente, os dados do survey de 2004 indicam que $91,0 \%$ dos domicílios mais pobres do município tiveram algum dos membros da família procurando atendimento de saúde no último ano, número bastante expressivo, sendo que em 49,5\% dos casos o atendimento tinha ocorrido até um mês antes da pesquisa. Também nesse caso, observa-se um elevado nível de cobertura do sistema público municipal de saúde, pois a proporção dos que buscaram serviços privados era inferior a $6 \%$.

$\mathrm{Na}$ comparação entre os dois surveys, observa-se que cerca $73 \%$ dos entrevistados nos dois estudos haviam usado o sistema público de saúde no ano anterior ao survey para serviços de rotina (excluindo os serviços de emergência). No caso de 2004 , a média para obter os atendimentos de saúde agendados era de trinta e nove dias, sendo que a mediana era de trinta dias.

Em síntese, os dados sobre a evolução do acesso a serviços públicos pelos $40 \%$ mais pobres de São Paulo apontam para um quadro de melhoria e de virtual universalização de alguns desses serviços. Cabe ressaltar que esse quadro é consistente com outras análises realizadas no âmbito das PNADs, tanto na escala nacional quanto na escala das regiões metropolitanas. Esses resultados indicam também que as questões relacionadas à qualidade vão se tornar crescentemente as mais relevantes na discussão a respeito das desigualdades nas condições de acesso a serviços públicos no Brasil.9

\section{AVALIAÇ̃̃o dOS USUÁRIOS E MECANISMOS DE ACESSO}

Tanto no survey de 1991 quanto no de 2004, foram realizadas perguntas relativas à avaliação que os usuários faziam dos serviços públicos por eles utilizados, visando aferir o grau de satisfação a partir de notas atribuídas a diferentes características do serviço. Cabe ressaltar que nem sempre tal modalidade de avaliação entre os mais pobres corresponde às expectativas de usuários mais sofisticados de serviços públicos, como as pessoas de maior escolaridade. De fato, as notas atribuídas aos serviços foram relativamente elevadas nos dois surveys, e tanto mais elevadas quanto menor a escolaridade.

No entanto, no caso do ensino fundamental, a nota média geral, queera de 6,4 (numa escala de o a 10) em 1991, subiu para 7,7 em 2004. Infelizmente não temos muitos dados comparativos que nos ajudem a interpre- 
tar esses dados. Por outro lado, só possuímos notas para aspectos específicos do ensino no survey de 2004. Neste, observamos que as melhores médias foram dadas à conservação das escolas $(7,6)$, freqüência dos professores $(7,6)$ e qualidade do ensino $(7,3)$, enquanto as menores notas foram dadas aos salários dos professores $(6,4)$ e segurança $(6,0)$.Além disso,em ambos os estudos, a segurança é apontada como o maior problema da escola! Em outras palavras, a questão da segurança nas escolas parece ser um aspecto fundamental e premente para a população de baixa renda, deixando em segundo plano a preocupação com a qualidade do ensino.

TABELA 4

Avaliação do ensino fundamental pelos chefes de família. São Paulo, 1991 e 2004.

\begin{tabular}{l|r|r}
\hline AVALIAÇÂ0 & \multicolumn{1}{c|}{ I991 } & 2004 \\
\cline { 1 - 2 } $\begin{array}{l}\text { Nota média } \\
\text { educação } \\
\text { (em geral) } \\
\text { entre o e 10 }\end{array}$ & 6,4 & \\
$\begin{array}{l}\text { Maior problema } \\
\text { da escola }\end{array}$ & Segurança & Segurança \\
$\begin{array}{l}\text { Necessidade } \\
\text { de ajuda } \\
\text { de terceiros } \\
\text { para obtenção } \\
\text { de vaga }\end{array}$ & $13,8 \%$ & $12,2 \%$ \\
\hline
\end{tabular}

Fonte: Cebrap, 1991 e 2004.

Merece destaque ainda a baixa proporção de pessoas que alegaram ter que recorrer a terceiros para conseguirvaga para seus filhos, $13,8 \% \mathrm{em}$ 1991 e 12,2\% em 2004. O survey mostra que mesmo quando recorria à alguém, a maior parte das pessoas que ajudavam era da própria escola (professores, diretores, etc.), isto é, indivíduos que têm obrigação institucional de prestar o serviço. Esse dado revela um indicador qualitativo de universalização, ou seja, o serviço não tem cobertura universal mas, de fato, chega à população, independentemente da interferência externa, especialmente de políticos.

Já no caso da saúde pública, a avaliação geral foi mais baixa nos dois estudos, mas a nota cresceu a taxas semelhantes: aumento de 1,3 na educação e 1,2 na saúde, como mostra a tabela abaixo.

Observamos também na tabela acima que há significativa variação na avaliação de aspectos específicos da saúde. Por exemplo, enquanto rapidez obtém a menor avaliação, os médicos obtêm as mais altas notas, nos dois anos. Como mencionado, o survey de 2004 identificou um tempo médio de trinta e nove dias para uma pessoa de baixa renda obter uma consulta pré-agendada, mostrando a razão da baixa nota em rapidez dos serviços. Esses dados indicam uma consistência que aumenta a confiança na avaliação feita, apesar do argumento, referido acima, de que a população mais pobre e com menos escolaridade seja pouco exigente em relação aos serviços públicos. 
TABELA 5

Avaliação de alguns aspectos do serviço público de saúde.

40\% mais pobres. São Paulo, 1991 e 2004. (Notas de 0 a 10 )

\begin{tabular}{|c|c|c|}
\hline ITENS & $199 \mid$ & 2004 \\
\hline & \multicolumn{2}{|c|}{ Hospital } \\
\hline Rapidez & 7,8 & 5,6 \\
\hline Limpeza & 8,6 & 7,8 \\
\hline Enfermeiras & 6,4 & 7,7 \\
\hline \multirow[t]{2}{*}{ Médicos } & 9,2 & 7,8 \\
\hline & \multicolumn{2}{|c|}{ Posto de saúde } \\
\hline Rapidez & 5,3 & 5.3 \\
\hline Limpeza & 6,7 & 7,9 \\
\hline Enfermeiras & 6,4 & 6,8 \\
\hline Médicos & 7,1 & 7,4 \\
\hline $\begin{array}{l}\text { Maior dificuldade } \\
\text { para atendimento }\end{array}$ & Filas & $\begin{array}{l}\text { Demora para } \\
\text { obter a consulta }\end{array}$ \\
\hline $\begin{array}{l}\text { Nota geral para } \\
\text { o atendimento }\end{array}$ & 5.5 & 6,7 \\
\hline
\end{tabular}

Fonte: Cebrap, 1991 e 2004

Quando consideramos os programas de transferência de renda, vale destacar que eles praticamente não existiam em 1991, sendo a única exceção o programa de distribuição de leite. Em 2004, 19\% da população pobre de São Paulo tinha acesso a pelo menos um dos programas de transferência de renda existentes, seja do governo municipal, estadual ou federal. Dentre os que recebiam dinheiro de algum programa, $50 \%$ declararam receber do programa Renda Mínima, da prefeitura de São Paulo; 24\% recebiam dos programas federais, o Bolsa-Família ou Bolsa-

[10] Após o período de realização do survey o programa Bolsa-Escola foi incluído dentro do programa BolsaFamília.
Escola, ${ }^{10}$ além do auxílio-gás, erradicação do trabalho infantil, etc; e 6,0\% do programa estadual Renda Cidadã. Finalmente, cabe destacar que $20 \%$ das famílias beneficiárias declararam receber benefícios de mais de um programa.

O ponto mais importante a ser destacado é que do total de famílias que recebem algum tipo de transferência de renda, $63 \%$ têm renda familiar per capita de até meio salário mínimo e $32 \%$ entre meio e um salário mínimo. Ou seja, 95\% dos que têm acesso ao programa são de fato os mais pobres e estão dentro dos critérios de elegibilidade dos diferentes programas. Além disso, o impacto desses programas na renda dos seus beneficiários não é desprezível: corresponde a 14\% de sua renda total. E esse impacto é maior entre as famílias com menor renda familiar:a transferência corresponde em média a $21 \%$ da renda. Tudo isso se torna ainda mais importante se consideramos que na década de 1990 a situação de emprego dessa camada da população foi extremamente deteriorada, como discutimos acima.

Todos esses programas juntos, no entanto, ainda estão longe de atender toda a população elegível. Em 2004, a cobertura dos programas de 
transferência de renda existentes ainda era muito baixa:chegava a apenas $28 \%$ da população com menos de meio salário mínimo per capita.

\section{CONCLUSÃo}

Embora a economia tenha se estabilizado a partir de 1994, o quadro da situação da população mais pobre de São Paulo aqui apresentado indica que os últimos quinze anos foram bem parecidos com a "década perdida", conforme analisada por Vilmar Faria. Resumidamente, observou-se o seguinte:

- Houve um quadro de agravamento das condições de acesso ao mercado de trabalho. Entre os mais pobres de São Paulo, a participação no mercado formal tornou-se amplamente minoritária, o que certamente tem conseqüencias muito perversas do ponto de vista das oportunidades econômicas dessas famílias;

I No que diz respeito à composição da renda familiar, caiu a participação das rendas auferidas a partir do trabalho principal e aumentou a participação dos rendimentos oriundos de trabalhos ocasionais e transferências governamentais (especialmente para as mulheres);

I Quanto à evolução dos rendimentos, observou-se uma melhora relativa. Há, porém, que se destacar que o ano de 1991 é relativamente problemático em termos comparativos. Segundo os dados da PNAD, a renda média per capita familiar ficou praticamente estável entre 1995 e 2004, bem como aumentou a proporção de pobres.

I Aumentou a cobertura de serviços públicos, em particular os de educação e saneamento básico, ainda que este último deixe de fora uma expressiva parcela da população pobre;

- A população $40 \%$ mais pobre de São Paulo avalia os serviços de educação de maneira mais positiva do que os de saúde, mas a avaliação de ambos cresce em proporções semelhantes na década;

I $O$ acesso a programas de transferência de renda passou a ter um peso significativo na composição da renda dos domicílios mais pobres.

Pensando nos próximos anos, vale destacar que, na esfera do trabalho, a perspectiva para os mais pobres não é muito animadora. $O$ setor privado da economia não parece ser capaz de oferecer empregos para o segmento mais pobre da população no futuro próximo, seja porque sua dinâmica de crescimento tem sido baixa, seja porque, com modernas tecnologias, as empresas geram cada vez menos empregos e exigem qualificação quando o fazem. Por outro lado, a oferta de emprego para os menos escolarizados, realizável pelo apoio aos setores fortemente empregadores, como a construção civil, não tem sido prioridade da política econômica nos últimos anos. Em suma, existem poucas esperanças de que as condições sociais possam avançar entre os mais pobres quando pensadas na perspectiva do mercado de trabalho. 
Recebido para publicação

em 04 de junho de 2006.

NOVOS ESTUDOS

CEBRAP

75 , julho 2006

pp. $173-183$
Por outro lado, embora a atuação do Estado, por meio de serviços públicos e políticas sociais, tenha conseguido "amortecer" os efeitos da forte deterioração das condições de trabalho por parte dos mais pobres, cabe perguntar até que ponto ele será capaz de continuar a cumprir esse papel no futuro próximo. Por um lado, a capacidade fiscal do estado no sentido de ampliar a rede de proteção social tem sido colocada em xeque pelo significativo aumento do gasto e da dívida pública. Por outro, os efeitos positivos da transição demográfica - que reduziu a pressão da demanda sobre serviços educacionais e de saúde - já se realizaram em grande medida, estando colocados daqui para a frente outros desafios nada negligenciáveis para as políticas sociais, como o envelhecimento populacional.

Argelina Cheibub Figueiredo, Haroldo da Gama Torres e Renata MiranDOLA BICHIR são pesquisadores do Cebrap. 